\title{
QUEEN'S
UNIVERSITY
BELFAST
}

\section{Active Circular Retro-directive Array}

Chepala, A., Fusco, V., \& Buchanan, N. (2019). Active Circular Retro-directive Array. IEEE Transactions on Antennas and Propagation. https://doi.org/10.1109/TAP.2019.2927628

\author{
Published in: \\ IEEE Transactions on Antennas and Propagation
}

\section{Document Version:}

Peer reviewed version

\section{Queen's University Belfast - Research Portal:}

Link to publication record in Queen's University Belfast Research Portal

\section{Publisher rights}

Copyright 2019 IEEE. This work is made available online in accordance with the publisher's policies. Please refer to any applicable terms of use of the publisher.

\section{General rights}

Copyright for the publications made accessible via the Queen's University Belfast Research Portal is retained by the author(s) and / or other copyright owners and it is a condition of accessing these publications that users recognise and abide by the legal requirements associated with these rights.

Take down policy

The Research Portal is Queen's institutional repository that provides access to Queen's research output. Every effort has been made to ensure that content in the Research Portal does not infringe any person's rights, or applicable UK laws. If you discover content in the Research Portal that you believe breaches copyright or violates any law, please contact openaccess@qub.ac.uk. 


\title{
Active Circular Retro-directive Array
}

\author{
Anil Chepala, Vincent Fusco and Neil Buchanan.
}

\begin{abstract}
Retro-directive arrays provide retransmission of signals back towards their source direction without prior knowledge of the source location. In this paper we explore the use of an active circular retro-directive array for up to $360^{0}$ retro-directive monostatic coverage. We also show by selectively choosing which bank of array elements are to be conjugated how we can control sectoral retro-directive coverage. Simulated and experimental results are provided for a 16-dipole element active circular retro-directive array at $2.4 \mathrm{GHz}$.
\end{abstract}

Index Terms - Circular array, Retro-directive array, Phaseconjugation, Beam forming.

\section{INTRODUCTION}

The ability to send an incident wave back in the direction from which it came is of practical interest in systems where self-tracking is required. Wave propagation physics shows that wave-front phase conjugation (PC) produces retro-directivity [1]. Examples in the microwave frequency range for repeater and wireless communications are given in [2], [3]. A passive retro-directive array was published by Van Atta [4], its application was limited to linear or planar arrays. Researchers explored the generation of retro-directivity using active phase conjugation techniques, of which the heterodyne mixing technique is the most popular and is known as Pon array [5]. This has the advantage of structural flexibility [6]. The performance limitations of this type of array was discussed in [7]. A robust means for phase conjugation by using IQ modulators was presented in [8-9] and we use this means for the circular retro-directive array proposed here.

In [10] we described how to provide complete $360^{\circ}$ retro-directive coverage in the azimuth plane by using a circular array (CA) fed with a Rotman Lens. Below we now explore the additional flexibility that can be afforded to a circular retro-directive array using individually selectable active phase conjugation units that are locally connected to each of the radiating elements comprising the array. It is noted that implementation using linear arrays usually result in $3 \mathrm{~dB}$ monostatic coverage around $\pm 40^{\circ}$, [11]. We show that in a CA the retro-coverage obtained depends on the number of activated conjugating elements in the array. We use the IQ mixing technique proposed in [12] for conjugation. The architecture used for the 16-element conjugating CA is shown in Fig. 1. Here each radiating element in the array is individually fed by its own phase conjugation board. Each conjugator can be connected to its radiating element on the CA via a single-polesingle-throw (SPST) absorptive switch or simply by powering it up. The array and the conjugator boards are designed to operate at 2.4 GHz.

This paper consists of the following sections. In section II we describe the phase conjugating circular array simulation procedure and key results. In section III we present the measured results obtained using phase conjugator banked switching and in section IV we conclude.

This work was supported by Queens's University of Belfast Studentship, and the UK Engineering and Physical Science Research Council (EPSRC) under Grants EP/N020391/1, EP/P000623/1.

A. Chepala, V. Fusco, and N. Buchanan are with The Centre for Wireless Innovation (CWI), The Institute of Electronics, Communications and Information Technology (ECIT), School of Electronics, Electrical Engineering and Computer Science (EEECS), Queen's University Belfast (QUB), Belfast BT39DT, United Kingdom (email: achepala01@qub.ac.uk, v.fusco@ecit.qub.ac.uk and n.buchanan@ecit.qub.ac.uk.)

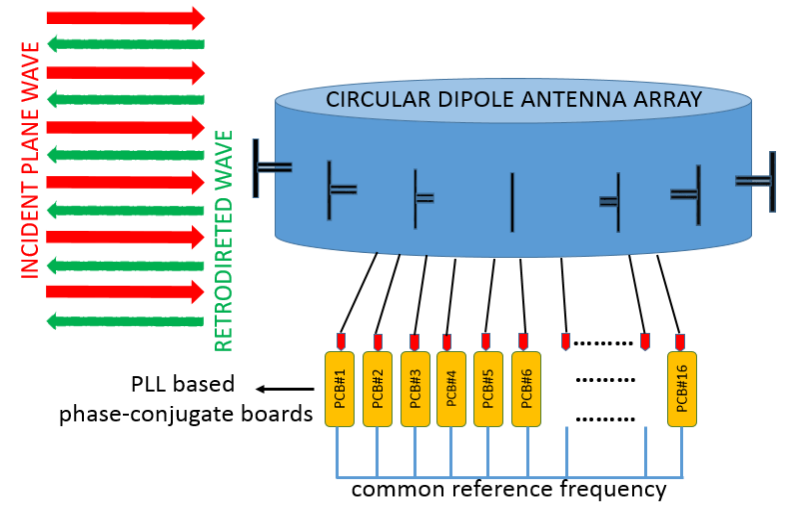

Fig. 1. Retro-directive Circular Array using Active Phase Conjugators.

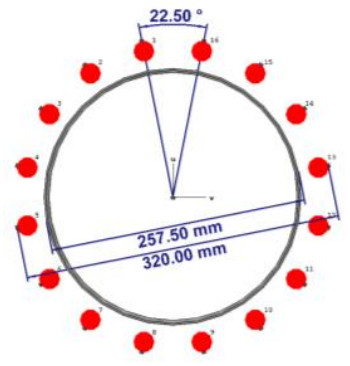

(a)

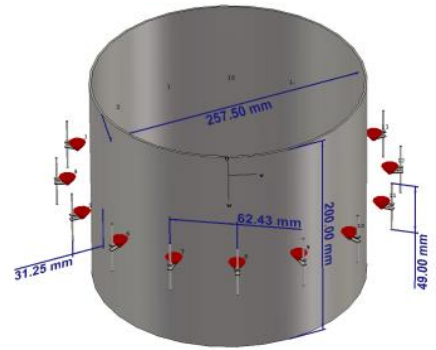

(b)
Fig. 2. (a) Top view and (b) Perspective view of the circular array.

\section{Active Retro-directive Circular Array Properties}

A retro-directive array redirects the incident signal back towards the direction of its source by utilizing phase conjugation. Phase conjugation is one of the basic techniques used for retro-direction with antenna arrays. The principle is similar to optics where the incident wave-front is retro-directed by preserving magnitude and phase information of the incident wave front and reflecting it from a phase conjugate mirror. In this paper the RF phase conjugation is done using phase conjugation boards (PCB). The antenna array spatially samples, radiating element wise, the signal incident upon it, conjugates this signal using PCBs and retransmits it, data can be extracted on receive and added on re-transmission as required see Fig. 1 . All the 16 dipole elements are arranged uniformly in a circle backed by metallic cylinder as shown in Fig. 2. The top view depicts the arrangements of the elements in the CA (see Fig 2 (a)) and the 3D model of the array with dimensions is shown in Fig. 2 (b). The induced signal voltages resulting from the per-element sampled in-coming wave-front are phase conjugated, and then used to re-excite the array in transmit mode. The signal then can retrace its path back to the location of the signal source provided the channel has not changed significantly during the above process. The means we use for direct per array element phase conjugation is shown in Fig. 3. A detailed description of its principle of operation, and performance is given in [11]. The conjugator is capable of operating with received signal strengths of $120 \mathrm{dBm}$ with better than $3^{0}$ of phase conjugation error (see inset Fig. $3)$. 


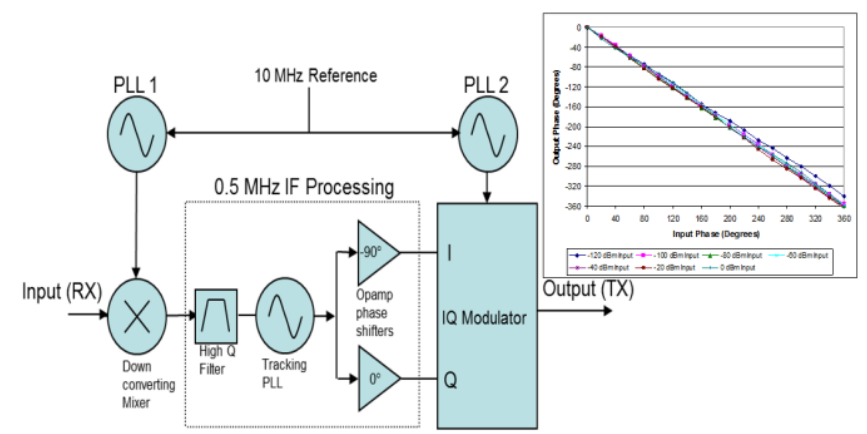

Fig. 3. Active Phase Conjugator Schematic with phase error plot.

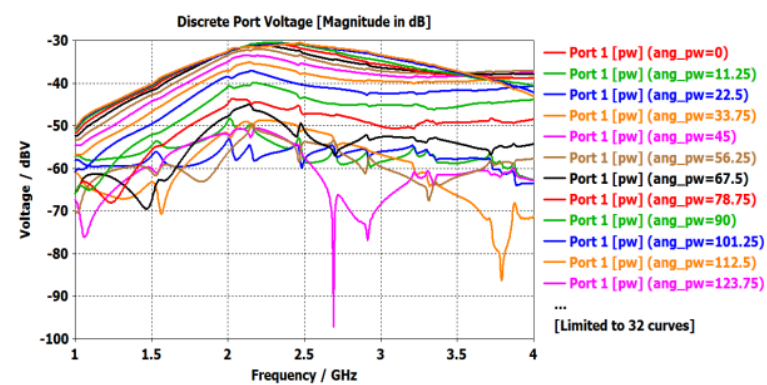

(a)

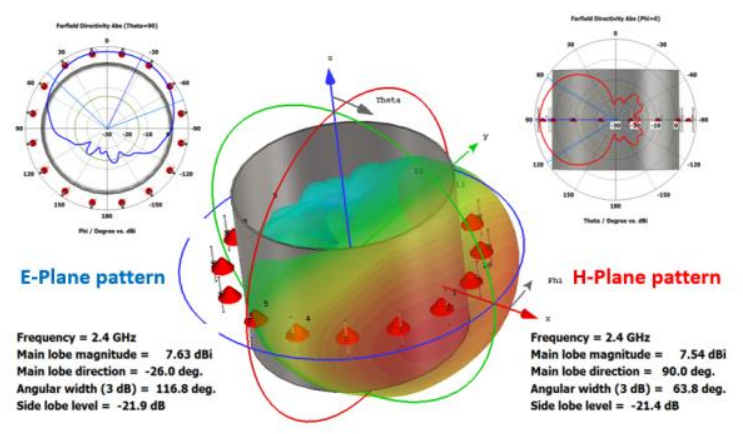

Fig. 4. Single dipole element radiation pattern.

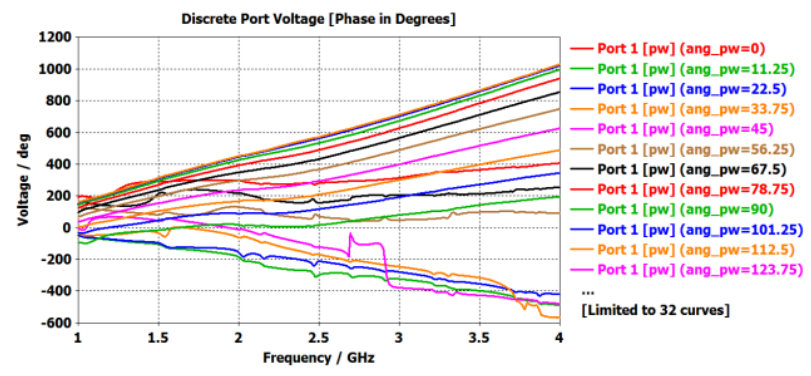

(b)

Fig. 5. (a) Magnitude (dB) and (b) phase $\left({ }^{\circ}\right)$ of Port-1(first element antenna input-port) voltages for different AOIs in steps of $22.5^{\circ}$.

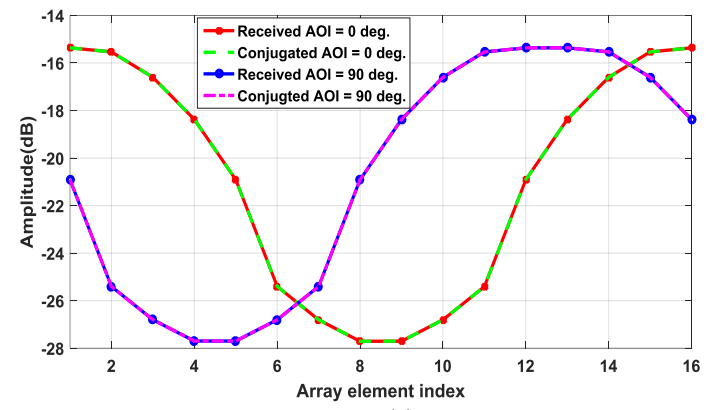

(a)

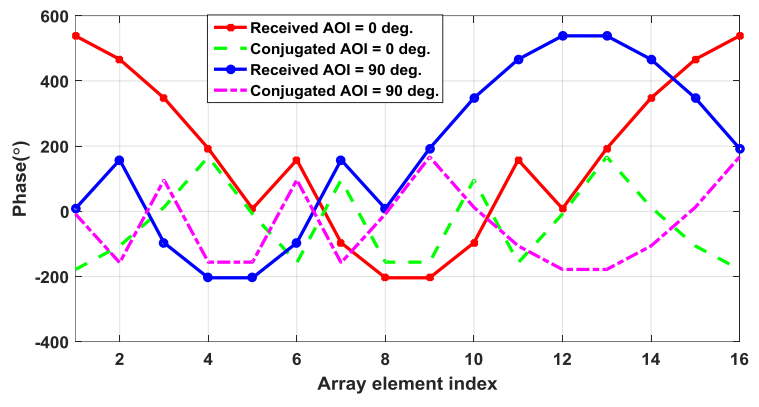

(b)

Fig. 6. (a) Magnitude (dB) and (b) phase $\left({ }^{\circ}\right)$ of port- 1 voltages for different $\mathrm{AOI}=0^{\circ}$ and $\mathrm{AOI}=90^{\circ}$

In-order to establish active phase conjugation on a circular array we first simulate using CST MW studio 3D simulation software a 16element dipole passive circular array designed for $2.4 \mathrm{GHz}$ operation. The dipole antennas are arranged around a circle of diameter $318 \mathrm{~mm}$ above a metallic cylinder diameter $257.5 \mathrm{~mm}$, height $200 \mathrm{~mm}$ and thickness $2 \mathrm{~mm}$. The dipoles are separated from the metallic cylinder by a distance of $31.25 \mathrm{~mm}$, which is approximately one-quarter wavelength at the array operating frequency, and the dipoles are uniformly separated by $22.5^{\circ}$ around the circumference of the circle (see Fig. 2 (b)). The simulated far-field pattern of single dipole element in 3D along with $\mathrm{E}$ and H-plane patterns is shown in Fig. 4.

To simulate the phase conjugation induced properties of the CA we follow the steps below:

(1) The CA is illuminated with a plane wave (interrogation signal) at different angles of incidence (AOI), this wave is polarization matched to that of the array elements.

(2) The induced voltages at the design frequency (i.e. $2.4 \mathrm{GHz}$ ) are recorded at the antenna terminals for each AOI as shown in Fig. 5 (a) and 5 (b).

(3) The voltages for each AOI are conjugated by post processing and then re-applied to corresponding elements in order to perform a simulation of the effect of retro-direction.
As an example the received and conjugated voltages (both amplitude and phase) at port-1 are shown in Fig 6 (a) and (b) respectively for $\mathrm{AOI}=0^{\circ}$ and $\mathrm{AOI}=90^{\circ}$. Using the above procedure we simulated the bi-static operation of the retro-directive array and measured its response. The simulated bi-static response for AOIs $-90^{\circ}, 0^{\circ}, 90^{\circ}$ along with measured at $\mathrm{AOI}=90^{\circ}$ is shown in Fig. 7 (a). When all 16 elements of the CA are activated and the plane wave AOIs are coincident with the angular positions of the array elements, the simulated (solid lines) and measured bi-static response (dotted lines) of the retro-directive $\mathrm{CA}$ is shown in Fig. 7(b).

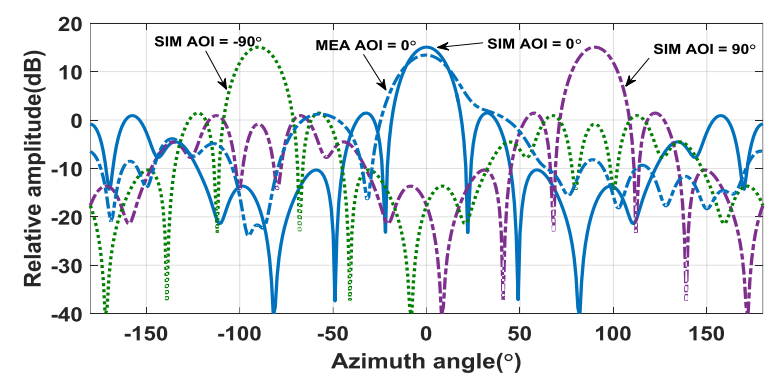

Fig. 7 (a). Simulated bi-static response for AOI $-90^{\circ}, 0^{\circ}$ and $90^{\circ}$ and measured response at AOI $0^{\circ}$. 


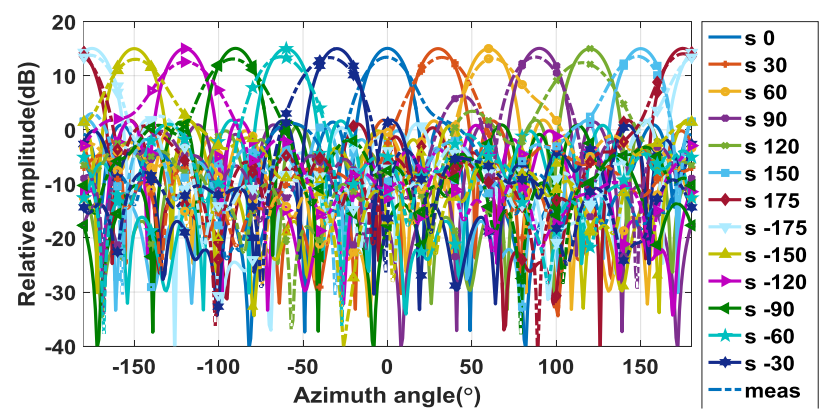

Fig. 7 (b). Simulated (solid) and measured (dotted) bi-static response $0^{0}$ to $360^{0}$ of the $\mathrm{CA}$ for $\mathrm{AOI}$ directions coincident with element angular locations, all 16 elements $\mathrm{ON}$

Next, the far-field bi-static radiation patterns with all 16 elements conjugated are simulated at $2^{0}$ angles between two adjacent radiators located at $0^{0}$ to $22.5^{0}$ for AOI $0^{0}$ to $22.5^{0}$. These results from Fig. 8 show in detail that retro-directive action with only about $0.25 \mathrm{~dB}$ maximum ripple occurs in the intermediate positions between the discrete element locations.

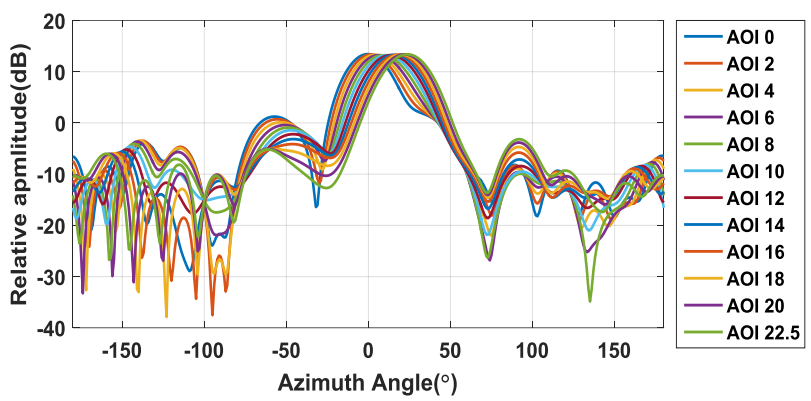

Fig. 8. Measured bi-static response for AOI $0^{0}$ to $22.5^{0}$.

\section{Selectively Switched Active Retro-directive Circular Array}

To explore further the flexibility of the test retro-directive array we study its ability for operation as phase conjugation units are selectively switched ON/OFF. When banks of adjacent elements are turned ON, the measured monostatic response of the array can be seen in Fig. 9. From Table I it can be seen that as more elements are switched on the $3 \mathrm{~dB}$ coverage of the array as well as it gain can be controlled. Gain can be seen to go from $7.6 \mathrm{~dB}$ simulated, $7.6 \mathrm{~dB}$ measured (1 element) to $15 \mathrm{~dB}$ simulated, $13.6 \mathrm{~dB}$ measured (16 elements), $3 \mathrm{~dB}$ monostatic beam-width from $117^{0}$ simulated, $118^{0}$ measured ( 1 element) to $360^{\circ}$ simulated, $360^{\circ}$ measured ( 16 elements). In all cases the bi-static side lobe levels remained below $-13.6 \mathrm{~dB}$.

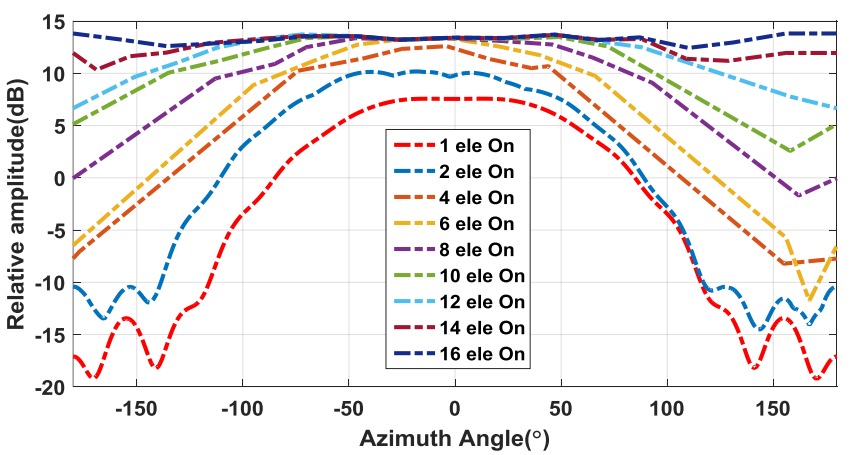

Fig. 9. Monostatic response of phase conjugated CA

\begin{tabular}{|c|c|c|c|c|c|c|c|c|c|}
\hline \multicolumn{10}{|c|}{ Simulated } \\
\hline $\begin{array}{l}\text { Number of } \\
\text { active } \\
\text { elements }\end{array}$ & 1 & 2 & 4 & 6 & 8 & 10 & 12 & 14 & 16 \\
\hline $\begin{array}{c}\text { Relative } \\
\text { amplitude } \\
\text { (dB) }\end{array}$ & 7.6 & 10.4 & 13.2 & 14.4 & 14.8 & 15.0 & 15.0 & 15.0 & 15.0 \\
\hline $\begin{array}{c}\text { Beam width } \\
\text { 3dB }\left(^{\circ}\right)\end{array}$ & 117 & 128 & 140 & 171 & 186 & 227 & 273 & 327 & 360 \\
\hline \multicolumn{10}{|c|}{ Measured } \\
\hline $\begin{array}{l}\text { Number of } \\
\text { active } \\
\text { elements }\end{array}$ & 1 & 2 & 4 & 6 & 8 & 10 & 12 & 14 & 16 \\
\hline $\begin{array}{c}\text { Relative } \\
\text { amplitude } \\
\text { (dB) }\end{array}$ & 7.6 & 10.2 & 12.6 & 13.4 & 13.3 & 13.5 & 13.7 & 13.6 & 13.6 \\
\hline $\begin{array}{c}\text { Beam width } \\
\text { 3dB }\left(^{\circ}\right)\end{array}$ & 118 & 128 & 144 & 136 & 175 & 212 & 235 & 326 & 360 \\
\hline
\end{tabular}

It is also evident that the actual array is producing gain of $13.6 \mathrm{~dB}$ which is equivalent to that of 10 dipole elements acting in concert. This occurs since only about half of the array can be illuminated with a plane wave from a particular AOI. The incident power level for retro-directive measurements was maintained at $-40 \mathrm{dBm}$ at the input of the conjugator boards. Retro-directive patterns were measured in both bi-static and monostatic modes in an anechoic chamber using the method discussed in [11].

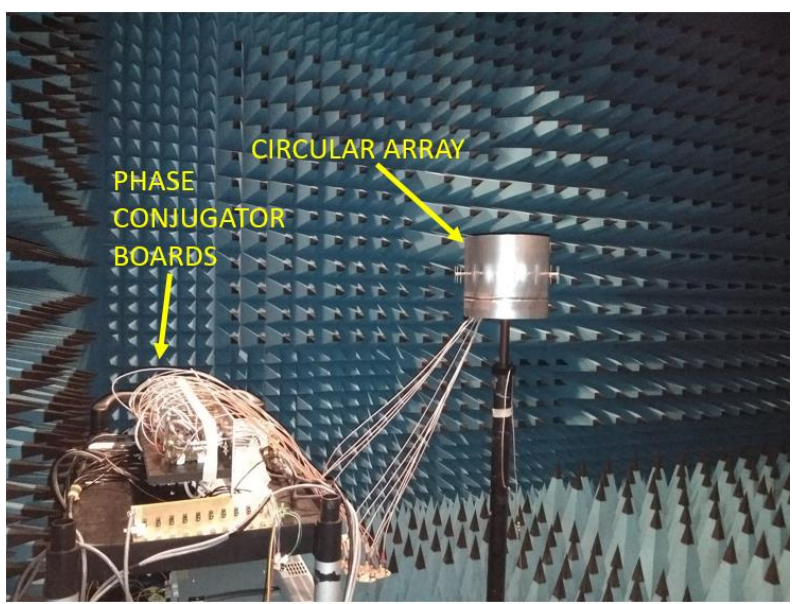

Fig. 10. Measurement set up for circular retro-directive array.

\section{CONCLUSIONS}

The operation of an active circular RDA for full $360^{\circ}$ degree coverage and its retro-directive properties under banked switching of elements in the array were presented. The results obtained show how the number of active elements on the circular array affect the production of well-formed retro-directive patterns monostatic coverage and gain. The proof of concept example given this paper should prove useful in tracking applications including radar and mobile communications.

\section{ACKNOWLEDGMENTS}

The authors would like to acknowledge the support given by Centre for Wireless Innovation (CWI) Scholarship at Queen's University Belfast and to the EPSRC under the grants EP/P000673/1, EP/NO20391/1. The authors would also like to thank Mr. Kieran Rainey 
for fabricating the circular array, testing the conjugate boards and helping with the pattern measurements.

\section{REFERENCES}

[1] B. Ya. Zel'dovich, N. F. Pilepetsky, and V. V. Shkunov, "Principles of Phase Conjugation". Berlin, Germany: SpringerVerlag, 1985.

[2] C. C. Cutler, R. Kompfner, and L. C. Tillotson, "A self-steering array repeater," Bell Syst. Tech. J., vol. 42, pp. 2013-2032, 1963.

[3] E. L. Gruenberg, H. P. Raabe, and C. T. Tsitsera, "Self-directional microwave communication system," IBM J. Res. Develop., vol. 18, no. 2, pp. 149-163, 1974.

[4] L. C. Van Atta, "Electromagnetic reflector," U.S. Patent 2908002 A, Oct. 6, 1959. [Online]. Available: http://www.google.co.uk/ patents/US2908002.

[5] C. Y. Pon, "Retro-directive array using the heterodyne technique," IEEE Trans. Antennas Propag., vol. AP-12, no. 2, pp. 176-180, Mar. 1964.

[6] C. Pobanz and T. Itoh, "A conformal retro-directive array for radar applications using a heterodyne phased scattering element," Proc. IEEE MTT-S Int. Microwave Symp. Dig., vol. 2, Orlando, FL, May 1995, pp. 905-908.

[7] B. Y. Toh, V. F. Fusco, and N. B. Buchanan, "Assessment of performance limitations of Pon retro-directive arrays," IEEE Trans. Antennas Propag., vol. 50, no. 10, pp. 1425-1432, Oct. 2002

[8] V. Fusco, C. B. Soo, and N. Buchanan, "Analysis and characterization of PLL-based retro-directive array," IEEE Trans. Microw. Theory Techn., vol. 53, no. 2, pp. 730-738, Feb. 2005.

[9] V. F. Fusco and N. B. Buchanan, "High-performance IQ modulator based phase conjugator for modular retro-directive antenna array implementation," IEEE Trans. Microw. Theory Techn., vol. 57, no. 10, pp. 2301-2306, Oct. 2009.

[10] A.Chepala, V.Fusco and M.Abbasi, "Circular Array Retrodirective Action Using a Rotman Lens Beamformer", in Eur. Conf. on Antennas and Propag. (EuCaP) , Apr. 2019.

[11] N. B. Buchanan, V. F. Fusco and M. van der Vorst, "SATCOM Retro-directive Array," in IEEE Transactions on Microwave Theory and Techniques, vol. 64, no. 5, pp. 1614-1621, May 2016.

[12] V. Fusco and N. Buchanan, "Dual-mode retro-directive/phased array," in Electronics Letters, vol. 45, no. 3, pp. 139-141, 29 January 2009. 